\title{
Study of interaction of low doses of ionizing radiation with selected pesticides on Artemia franciscana
}

\author{
Michaela Špalková1, Katarína Beňová1, Petr Dvořák², Marcel Falis ${ }^{3}$, Andrej Renčko ${ }^{1}$ \\ ${ }^{1}$ University of Veterinary Medicine and Pharmacy in Košice, Department of Biology and Genetics, \\ Košice, Slovak Republic \\ ${ }^{2}$ University of Veterinary and Pharmaceutical Sciences Brno, Faculty of Veterinary Hygiene and Ecology, \\ Department of Biochemistry and Biophysics, Brno, Czech Republic \\ ${ }^{3}$ University of Veterinary Medicine and Pharmacy in Košice, Department of Pharmacology and Toxicology, \\ Košice, Slovak Republic
}

Received July 2, 2014

Accepted October 22, 2014

\begin{abstract}
The aim of our study was to observe the effect of low doses of ionizing radiation, azoxystrobin and glyphosate separately as well as in their mutual combinations on the lethality of Artemia franciscana. Increasing intensity of agricultural production leads to continual exposure of animals to pesticide residues. Animals could be exposed to these negative factors in case of possible nuclear accident. A total of 1000 nauplia, randomly placed in 20 groups ( 1 control and 19 experimental groups), were irradiated with gamma rays $(0,20,30,40$ or 50 Gy) and were kept in solution of standardized sea water and standardized sea water with addition of pesticides (azoxystrobin at a concentration of $0.0001 \mathrm{~g} \cdot 1^{-1}$ and glyphosate at a concentration of $0.5 \mathrm{~g} \cdot \cdot^{-1}$ individually or in combination). A significant increase of lethality was observed after 48, 72 and $96 \mathrm{~h}$ of exposure to only azoxystrobin, but also in the group exposed to the combined effect of azoxystrobin and glyphosate at all time intervals. On the other hand, a significant decrease of lethality was observed in those groups exposed to ionizing radiation even at the dose of $30 \mathrm{~Gy}$ at all time intervals compared to non-irradiated groups. These results confirm the toxicity of azoxystrobin to aquatic organisms; non-toxicity of glyphosate to crustaceans and support the theory of radiation hormesis at the level of 30 Gy radiation dose.
\end{abstract}

Azoxystrobin, crustaceans, glyphosate, hormesis, ionizing radiation

Considerable expansion of human population combined with increasing demands on food quality resulted in more intensive agricultural production. This increase in intensity was associated with increased use of pesticides, higher load on the ecosystem and considerable economic loss. Increasing pollution brings about increasing concern for the influence of xenobiotics on live systems in general and, subsequently, on individual organ systems. The most commonly used pesticides are azoxystrobin (fungicide) and glyphosate (herbicide).

Glyphosate belongs among non-selective herbicides. Preparations based on this substance contain the active ingredient at $41 \%$ and $1 \%$ concentrations. In addition to the active ingredient they contain also a mixture of isopropanol amine (IPA) salt and other additives, such as antifoaming and colouring ingredients, biocides and $\mathrm{pH}$-adjusting inorganic ions (Bradberry et al. 2004).

Azoxystrobin is a wide spectrum fungicide acting against various diseases of agricultural and decorative plants. It exhibits a wide spectrum effect against common species of pathogenic fungi (Anonymus 1996). It is one of the most frequently used fungicides worldwide (Thoms on 1997).

Ionizing radiation has affected the human population from the beginning of its existence in the form of cosmic radiation and also due to naturally radioactive minerals. The progressing modernization and industrial and medicinal development brought about additional artificial anthropogenic sources of radiation. Notably, nuclear weapon testing, utilization of nuclear

Address for correspondence:

Michaela Špalková

Department of Biology and Genetics

University of Veterinary Medicine and Pharmacy in Košice

Komenského 73, 04181 Košice, Slovak Republic

Phone: +421904557374

E-mail: mimi.spalkova@gmail.com

http://actavet.vfu.cz/ 
energy (Chernobyl, Fukushima), and diagnostic or therapeutic medical equipment based on ionizing radiation.

Effects of higher doses of gamma radiation have been described by a number of authors involving both vertebrates (Sesztáková et al. 1996; Falis et al. 2004; Beňová et al. 2006) and invertebrates, e.g. Artemia salina (Dvořák and Beňová 2002). On the other hand, low doses of ionizing radiation can also have positive effects (the so-called radiation hormesis). This involves stimulation of many processes, such as germination of seeds and growth of many plant species, increase in the activity of individual enzymes, stimulation of bacterial division and isolated mammalian cells, prolonged life of water plankton, drosophila, mice, and rats exposed to chronic irradiation with extremely low doses, increased radio-resistance to repeated irradiation with high doses (the so-called adaptive response), and decreased mortality of humans due to oncologic diseases (Luckey 1994; Sanders 2010).

The current trend is to decrease the number of animal experiments to a minimum. According to the Directive 86/609/EEC, animal means any live non-human vertebrate, including free-living larval and/or reproducing larval forms, but excluding foetal or embryonic forms. The EU also efforts to reduce the number of trial vertebrates. This can be realized by a substitution of conventional tests with alternative biotests. Unlike insulated tissue cultures, the biotest in plankton animals represents a model based on a complex live organism. These are presented and described in experiments, which are more similar to natural conditions compared to the inbreeding lines of trial vertebrates (Dvořák et al. 2012a). For this reason an alternative biotest of the $2^{\text {nd }}$ generation carried out on Artemia franciscana was used in this study (Dvořák and Beňová 2002). In a majority of older

Table 1. Schema of experimental design, interactions of different doses of irradiation (Gy) and different concentrations of azoxystrobin and glyphosate $\left(\mathrm{mg} \cdot \mathrm{l}^{-1}\right)$.

\begin{tabular}{lccc}
\hline $\begin{array}{l}\text { Control and } \\
\text { experimental groups }\end{array}$ & $\begin{array}{c}\text { Concentration of } \\
\text { azoxystrobin }\left(\mathrm{mg} \cdot \mathrm{l}^{-1}\right)\end{array}$ & $\begin{array}{c}\text { Concentration of } \\
\text { glyphosate }\left(\mathrm{mg} \cdot \mathrm{l}^{-1}\right)\end{array}$ & $\begin{array}{c}\text { Dose of ionizing } \\
\text { radiation }(\mathrm{Gy})\end{array}$ \\
\hline C & 0 & 0 & 0 \\
20Gy & 0 & 0 & 20 \\
30Gy & 0 & 0 & 30 \\
40Gy & 0 & 0 & 40 \\
50Gy & 0 & 0 & 50 \\
A & 0.1 & 0 & 0 \\
G & 0 & 500 & 0 \\
AG & 0.1 & 500 & 0 \\
A20Gy & 0.1 & 0 & 20 \\
A30Gy & 0.1 & 0 & 30 \\
A40Gy & 0.1 & 0 & 40 \\
A50Gy & 0.1 & 0 & 50 \\
G20Gy & 0 & 500 & 20 \\
G30Gy & 0 & 50 & 30 \\
G40Gy & 0 & 500 & 40 \\
G50Gy & 0 & 500 & 50 \\
AG20Gy & 0.1 & 500 & 20 \\
AG30Gy & 0.1 & 500 & 30 \\
AG40Gy & 0.1 & 500 & 40 \\
AG50Gy & 0.1 & 500 & 50 \\
\hline & & & \\
\hline
\end{tabular}


studies Artemia franciscana was presented as Artemia salina, the change arising due to taxonomic revision in nomenclature of the genus Artemia (Dvořák et al. 2012b).

The aim of the present experiment was to compare the influence of various doses of gamma radiation before exposure of Artemia franciscana to individual pesticides or their combination on their lethal effect.

\section{Materials and Methods}

The experiment was carried out on Artemia franciscana hatched in sea-water of the following composition: $\mathrm{NaCl} 23.900 \mathrm{~g} \cdot \mathrm{l}^{-1}, \mathrm{MgCl}_{2} \cdot 6 \mathrm{H}_{2} \mathrm{O} 10.830 \mathrm{~g} \cdot \mathrm{l}^{-1}, \mathrm{CaCl}_{2} \cdot 6 \mathrm{H}_{2} \mathrm{O} 2.250 \mathrm{~g} \cdot \mathrm{l}^{-1}, \mathrm{KCl} 0.680 \mathrm{~g} \cdot \mathrm{l}^{-1}, \mathrm{Na}_{2} \mathrm{SO}_{4} \cdot 10 \mathrm{H}_{2} \mathrm{O} 9.060 \mathrm{~g} \cdot 1^{-1}$, $\mathrm{NaHCO}_{3} 0.200 \mathrm{~g} \cdot \mathrm{l}^{-1}, \mathrm{SrCl}_{2} \cdot 6 \mathrm{H}_{2} \mathrm{O} 0.040 \mathrm{~g} \cdot \mathrm{l}^{-1}, \mathrm{KBr} 0.099 \mathrm{~g} \cdot \mathrm{l}^{-1}, \mathrm{H}_{3} \mathrm{BO}_{3} 0.027 \mathrm{~g} \cdot \mathrm{l}^{-1} ; \mathrm{pH} 8.31$ (Dvořák et al. 2005). Ten freshly hatched nauplia were placed to polystyrene Petri dishes of a diameter of $60 \mathrm{~mm}$, using $10 \mathrm{ml}$ of sea-water in total (including the sample). Investigations were carried out with azoxystrobin at a concentration of 0.0001 $\mathrm{g} \cdot \mathrm{l}^{-1}$ and glyphosate at a concentration of $0.5 \mathrm{~g} \cdot \mathrm{l}^{-1}$ individually or in combination. All investigated solutions were prepared in sea-water. Nauplia were irradiated with gamma rays, the absorbed doses were 20, 30, 40 or 50 Gy $\left({ }^{60} \mathrm{Co}\right.$, Chisostat, Chirana, SR) at a dose output of $113.6 \mathrm{~Gy} \cdot \mathrm{h}^{-1}$.

Doses of radiation were set in order to present various lethal doses to A. fransiscana in the experiment. Doses of pesticides were set as the multiples of its recommended doses for agricultural use. Azoxystrobin was used at a dose $\times 21.3$ higher than the recommended dose, to cause significant lethality of Artemia. Glyphosate was used at a dose $\times 12285$ higher than the recommended dose, because producers declare a non-toxic effect of glyphosate to non-plant organisms.

Nauplia were randomly placed in 20 groups, 1 control and 19 experimental groups (Table 1). Each group comprised 50 nauplia subdivided to 5 separate groups (dishes), 10 individuals in each. In total 1000 nauplia were investigated. The Petri dishes were placed into previously disinfected thermostat (Kočišová 2005) set to $20( \pm 1){ }^{\circ} \mathrm{C}$.

At the time intervals of 24, 48, 72, and $96 \mathrm{~h}$ live artemia were counted. Results from experimental groups were compared with the control and evaluated statistically. Groups exposed to azoxystrobin were also compared.

Dean-Dixon's test (Eckschlager et al. 1980) was used to eliminate distant results. Significance of differences between individual groups was determined according to Hayes (1991). Differences were considered significant at $P<0.05$.

\section{Results}

In the control group, the maximum lethal effect on Artemia franciscana was observed at the level of $4 \%$ after $72 \mathrm{~h}$. Observation after 24-h exposure showed no significant differences in lethality between control and experimental groups with the exception of non-irradiated group exposed to both pesticides (AG). After 48-h exposure there were significant differences $(P<0.05)$ in lethality between groups exposed to azoxystrobin $(\mathrm{A})$, azoxystrobin exposed and irradiated with the doses of $40 \mathrm{~Gy}$ (A40Gy), and $50 \mathrm{~Gy}$ (A50Gy), groups exposed to glyphosate and irradiated with the doses of 20 Gy (G20Gy), 40 Gy (G40Gy), and 50 Gy (G50Gy), exposed to the combination of azoxystrobin and glyphosate (AG), exposed to both pesticides and irradiated with the doses of $20 \mathrm{~Gy}$ (AG20Gy), 40 Gy (AG40Gy), and 50 Gy (AG50Gy) compared to the control. After 72-h and 96-h exposure, significantly increased $(P<0.05)$ lethality was observed compared to the control in the same groups as after 48-h exposure (Table 2).

In the group exposed to azoxystrobin $56 \%$ lethality was observed after $48 \mathrm{~h}$ of exposure. However, in the same time interval, significantly decreased $(P<0.05)$ lethality was recorded in the groups exposed to both azoxystrobin and ionizing radiation at a dose of 20 Gy (A20Gy) and 30 Gy (A30Gy) compared to azoxystrobin exposed non-irradiated group (A). After $72 \mathrm{~h}$, lethality in groups A20Gy and A30Gy was also significantly decreased $(P<0.05)$ compared to the azoxystrobin exposed group (A). Similar situation with regard to groups A20Gy and A30Gy compared to group A was observed after $96 \mathrm{~h}$ of exposure.

Observation of the effect of glyphosate after 48, 72, and $96 \mathrm{~h}$ of exposure showed significantly increased $(P<0.05)$ lethality in groups irradiated with doses $20 \mathrm{~Gy}$ (G20Gy), 40 Gy (G40Gy) and 50 Gy (G50Gy) compared to glyphosate exposed nonirradiated group $(\mathrm{G})$ and group irradiated with the dose of 30 Gy (G30Gy). 
Table 2. Lethality (\%) of Artemia franciscana after exposure to irradiation, azoxystrobin and glyphosate separately and in their mutual combinations in investigated intervals.

\begin{tabular}{|c|c|c|c|c|c|c|c|c|c|c|c|c|}
\hline \multirow{2}{*}{$\begin{array}{l}\text { Experimental } \\
\text { group }\end{array}$} & \multicolumn{3}{|c|}{$24 \mathrm{~h}$} & \multicolumn{3}{|c|}{$48 \mathrm{~h}$} & \multicolumn{3}{|c|}{$72 \mathrm{~h}$} & \multicolumn{3}{|c|}{$96 \mathrm{~h}$} \\
\hline & $X$ & $\mathrm{~N}$ & $\mathrm{~s}$ & $X$ & $\mathrm{~N}$ & S & $\mathrm{X}$ & $\mathrm{N}$ & S & $\mathrm{x}$ & $\mathrm{n}$ & SD \\
\hline$\overline{\mathrm{C}}$ & 0 & 5 & 0 & 0 & 5 & 0 & 0 & 5 & 0 & 4 & 5 & 4.3 \\
\hline 20Gy & 2 & 5 & 4.3 & 2 & 5 & 4.3 & 2 & 5 & 4.3 & 2 & 5 & 4.3 \\
\hline 30Gy & 0 & 5 & 0 & 0 & 5 & 0 & 0 & 5 & 0 & 0 & 5 & 0 \\
\hline 40Gy & 0 & 5 & 0 & 0 & 5 & 0 & 6 & 5 & 4.3 & 12 & 5 & 4.3 \\
\hline 50Gy & 0 & 5 & 0 & 0 & 5 & 0 & 0 & 5 & 0 & 14 & 5 & 4.3 \\
\hline A & 6 & 5 & 8.6 & $56^{*}$ & 5 & 12.9 & $74^{*}$ & 5 & 8.6 & $86^{*}$ & 5 & 17.2 \\
\hline A20Gy & 4 & 5 & 4.3 & 6 & 5 & 4.3 & 6 & 5 & 4.3 & 8 & 5 & 4.3 \\
\hline A30Gy & 0 & 5 & 0 & 2 & 5 & 4.3 & 2 & 5 & 4.3 & 2 & 5 & 4.3 \\
\hline A40Gy & 6 & 5 & 4.3 & $48^{*}$ & 5 & 12.9 & $62 *$ & 5 & 17.2 & $86^{*}$ & 5 & 8.6 \\
\hline A50Gy & 2 & 5 & 4.3 & $42 *$ & 5 & 8.6 & $68^{*}$ & 5 & 8.6 & $88^{*}$ & 5 & 8.6 \\
\hline G & 0 & 5 & 0 & 0 & 5 & 0 & 0 & 5 & 0 & 0 & 5 & 0 \\
\hline G20Gy & 2 & 5 & 4.3 & $12 *$ & 5 & 8.6 & $16^{*}$ & 5 & 8.6 & $18^{*}$ & 5 & 4.3 \\
\hline G30Gy & 0 & 5 & 0 & 4 & 5 & 4.3 & 4 & 5 & 4.3 & 6 & 5 & 4.3 \\
\hline G40Gy & 0 & 5 & 0 & $18^{*}$ & 5 & 4.3 & $18^{*}$ & 5 & 4.3 & $28^{*}$ & 5 & 4.3 \\
\hline G50Gy & 0 & 5 & 0 & $20 *$ & 5 & 4.3 & $22 *$ & 5 & 4.3 & $28 *$ & 5 & 4.3 \\
\hline $\mathrm{AG}$ & $36^{*}$ & 5 & 21.5 & $44^{*}$ & 5 & 17.2 & $52 *$ & 5 & 21.5 & $60 *$ & 5 & 25.8 \\
\hline AG20Gy & 10 & 5 & 8.6 & $22 *$ & 5 & 8.6 & $22 *$ & 5 & 8.6 & $28 *$ & 5 & 8.6 \\
\hline AG30Gy & 4 & 5 & 4.3 & 6 & 5 & 4.3 & 6 & 5 & 4.3 & 8 & 5 & 8.6 \\
\hline AG40Gy & 6 & 5 & 8.6 & $16^{*}$ & 5 & 4.3 & $18^{*}$ & 5 & 4.3 & $24 *$ & 5 & 4.3 \\
\hline AG50Gy & 10 & 5 & 4.3 & $34^{*}$ & 5 & 4.3 & $48^{*}$ & 5 & 4.3 & $54^{*}$ & 5 & 4.3 \\
\hline
\end{tabular}

$\mathrm{x}$ - lethality in \%; $\mathrm{n}$ - number of tested groups; SD - standard deviation; * - significance in comparison with the control $(P=0.05)$

In the groups exposed to the combined effect of azoxystrobin and glyphosate already at 24-h interval a significant decrease $(P<0.05)$ in lethality was observed in all irradiated groups (AG20Gy, AG30Gy, AG40Gy, AG50Gy) compared to the non-irradiated group (AG). After 48, 72 and $96 \mathrm{~h}$, significantly decreased $(P<0.05)$ lethality was recorded in groups irradiated with doses 20 Gy (AG20Gy), 30 Gy (AG30Gy), and 40 Gy (AG40Gy) in comparison with the non-irradiated dose (AG). However, in the group AG30Gy significantly decreased $(P<0.05)$ lethality was recorded after $48 \mathrm{~h}$ compared to AG20Gy and AG50Gy, and after 72 and $96 \mathrm{~h}$ compared to groups AG20Gy, AG40Gy, and AG50Gy.

\section{Discussion}

According to the Pesticide manual (Tomlin 2001) azoxystrobin is characterised as dangerous to fish and other water fauna which was confirmed by its toxicity in the present experiment. Similar toxic effect on Artemia franciscana was observed by Falis et al. (2010).

The principle of its effect is based on inhibition of respiration by blocking electron transfer between cytochrome and cytochrome $c_{1}$ on both sides of the oxidation plane. It exhibits a wide spectrum effect against pathogenic fungi, particularly those from the genera Ascomycetes, Basidiomycetes, Deuteromycetes, and Oomycetes. It inhibits germination of spores and mycelium growth (Tomlin 2001). 
Glyphosate was included in the list of risk substances relevant in the Slovak Republic within the programme for decreasing pollution of waters by harmful and extremely harmful substances for which it is necessary to develop a scheme of measures ensuring decreased pollution of waters with these substances. With regard to the current use of glyphosate in agriculture it is necessary to monitor it regularly in water environment (Anonymous 2002).

Glyphosate exhibits a wide spectrum herbicidal effect against annual and perennial weeds. Environmental properties of this herbicide, such as its immobility in soil, rapid soil inactivation and soil biodegradation are unknown. This herbicide is virtually nontoxic to "non-plant" forms of life, for example to water fauna, birds, animals and humans (Malik et al. 1989). Results of our experiment proved that this herbicide is not toxic to water crustaceans. Herbicides based on glyphosate (e.g. Roundup ${ }^{\circledR}$ ) are frequently used in water environment. On the other hand, the results of some experiments showed that glyphosate is toxic even to non-plant forms of organisms. Investigations were carried out regarding the toxicity of four forms of glyphosate to water fauna (Vibrio fischeri, Selenastrum capricornutum, Skeletonema costatum, Tetrahymena pyriformis, Euplotes vannus, Ceriodaphnia dubia, and Acartia tonsa). There toxicity was as follows: POEA (polyoxyethylene amine) $>$ Roundup ${ }^{\circledR}>$ glyphosate acid $>$ isopropylamine glyphosate salt (IPA). Toxicity of glyphosate acid resulted from its considerable acidity (Tsui and Chu 2003). In our experiment the product Roundup ${ }^{\circledR}$ was used. Even Mann and Bidwell (1999) investigated the acute toxicity of glyphosate acid, IPA, and three glyphosate salts to adult frogs and tadpoles of four species of Southern Western Australian frogs and observed considerable sensitivity of juvenile forms of the species Litoria moorei. Relyea (2005) studied toxicity of Roundup ${ }^{\mathbb{R}}$ to North American frog species. They recorded the death of $96-100 \%$ of larval forms and $68-86 \%$ of juvenile forms.

Ionizing radiation is not detected by our senses and as a rule, we learn about its presence only after manifestation of its negative effects. The negative influence of ionizing radiation was indicated by the results of Beňová et al. (2007) who reported similar lethality of irradiation with a dose of $50 \mathrm{~Gy}$ as that recorded in our experiment. The present experiment showed that exposure to glyphosate and ionizing radiation at doses of 20, 40, and 50 Gy resulted in the summarization of negative effects of these factors. Negative effects of all factors are based on attacking the enzyme systems of cells, where also occurs the summarization of damaging enzyme systems. In comparison of groups C, 20-50 Gy vs. G, G20-G50 Gy it is apparent that glyphosate alone is without any effect on the lethality, but in case of irradiation at doses of 20, 40, and 50 Gy it increases the lethality caused by irradiation. In case of irradiation at a dose of $30 \mathrm{~Gy}$, effect of radiation hormesis was observed. Ionizing radiation affects all life on earth. Living organisms are adapted to natural doses of radiation background and further low doses in addition cause positive effects. The positive effect of irradiation is based on the stimulation of endonucleases, which leads to an increase of reparation mechanisms in irradiated organisms. The backset comes with higher rations of ionizing radiation, which cause stochastic effects at first with subsequent deterministic negative effects. Stochastic effects are based on irreversible damage of DNA, especially inhibitory genes for oncogenes. Similar results indicating radiation hormesis at a dose of 10 Gy were reported by Beňová et al. (2007) who, however, investigated the interaction of heavy metals $(\mathrm{Cd}, \mathrm{Cr})$ and radiation. The magnitude of doses in tens of Gy should be related to phylogenetic position of invertebrates, crustaceans of the genus Artemia. Many authors of epidemiological studies supported the concept that low doses are beneficial to health (Luckey 1994; Cohen 1995; Jawarowski 1995; Pollycove 1997). The most frequently presented essence of hormesis is the activation and stimulation of adaptive and reparative processes and immune mechanisms by low doses of ionizing radiation which subsequently results in increased immunity of the body (Sanders 2010; Luckey 1991). 
In conclusion we can state that the results presented in this study confirm that azoxystrobin is highly toxic for aquatic organisms; glyphosate is non-toxic to crustaceans of species Artemia franciscana; and the results support the theory of radiation hormesis at the level of $30 \mathrm{~Gy}$ radiation dose. Animals could be exposed to the above discussed negative factors in case of a nuclear accident.

\section{Acknowledgment}

The present study was supported by The National Reference Laboratory for Pesticides SR, UVLF-KE and the project of IGA VFU Brno 92/2011/FVHE, (IG212112).

\section{References}

Anonymous 1986: Council Directive of 24 November 1986 on the approximation of laws, regulations and administrative provisions of the Member States regarding the protection of animals used for experimental and other scientific purposes $(86 / 609 / \mathrm{EEC})$

Anonymous 1996: Technical information bulletin for heritage fungicide. Zeneca Professional Products: Wilmington, $\mathrm{DE} ; 4 \mathrm{p}$.

Anonymous 2002: EC Health \& Consumer protection directorate-general: Review report for the active substance glyphosate. 6511/VI/99-final.

Beňová K, Cigánková V, Falis M, Šmajda B 2006: Clinical symptoms and histological changes in Poecilia reticulata following gamma-rays irradiation. Acta Vet Brno 75: 557-560

Beňová K, Dvořák P, Falis M, Sklenář Z 2007: Interaction of low dosis of ionizing radiation, potassium dichromate and cadmium chloride in Artemia franciscana biotest. Acta Vet Brno 76: 35-40

Bradberry SM, Proudfoot AT, Vale JA 2004: Glyphosate poisoning. Toxicol Rev 23: 159-167

Cohen BL 1995: Test of the linear no-threshold theory of radiation carcinogenesis in the low dose, low dose region. Health Phys 68: 157-174

Dvořák P, Beňová K 2002: The investigation of interactions of low doses of ionizing radiation and risk factors by means of Artemia salina biotest. Folia Vet 46: 195-197

Dvořák P, Beňová K, Vitek J 2012b: Alternative biotest on Artemia franciscana. In Ecotoxicology; INTECH: Rijeka, Croatia, pp. 51-74

Dvořák P, Sucman E, Beňová K 2005: The development of a ten day biotest using Artemia salina nauplii. Biologia, Bratislava 60: 593-597

Dvořák P, Žd'árský M, Beňová K, Špalek M 2012a: Selected morphological changes in Artemia franciscana after ionizing radiation exposure. Bull Environ Contam Toxicol 89: 286-291

Eckschlager K, Horsák I, Kodejš Z 1980: Scoring of analytical results and methods (in Czech). SNTL/ALFA: Praha, $306 \mathrm{p}$.

Falis M, Beňová K, Toropila M, Sesztáková E, Legáth J 2004: Changes in the activity of selected adaptive enzymes in chicken liver after single gamma irradiation. Bull Vet Inst Pulawy 48: 503-506

Falis M, Śpalek M, Legáth J, Krupicer I 2010: Observing the interaction of selected pesticides and heavy metals on the lethality of Artemia franciscana (in Slovak). X. Risk factors of food chain, Nitra, Slovakia, pp. 68-72

Hayes WJ 1991: Dosage and other factors influencing toxicity. In: Hayes WJ, Laws ER (Eds.): Handbook of pesticide toxicology. Academic Press, San Diego, CA, pp. 39-105

Jawarowski Z 1995: Beneficial radiation. Nukleotika 40: 3-12

Kočišová A 2005: Disinfection of environment - part of preventive measures in infectious diseases and parasitic infections in animal husbandry (in Slovak). Disinfection, Disinsection, Deratisation 14: 149-153

Luckey TD 1991: Radiation hormesis. CRC Press: Boca Raton, FL, 306 p.

Luckey TD 1994: Radiation hormesis in cancer mortality. Chin Med J Engl 107: 627-630

Malik J, Barry G, Kishore G 1989: The herbicide glyphosate. BioFactors 2: 17-25

Mann RM, Bidwell JR 1999: The toxicity of glyphosate and several glyphosate formulations to four species of southwestern australian frogs. Arch Envron Contam Toxicol 36: 193-199

Pollycove M 1997: The rise and the fall of the linear no-threshold theory of radiation carcinogenesis. Nuclear News 40: $34-37$

Relyea RA 2005: The lethal impact of Roundup on aquatic and terrestrial amphibians. Ecol Appl 15: 1118-1124

Sanders ChL 2010: Radiation hormesis and the linear-no-threshold assumption. Springer-Verlag: Berlin, London, New York, $217 \mathrm{p}$.

Sesztáková E, Toropila M, Beňová K 1996: Post-irradiation changes in the peripheral blood of chickens. Folia Vet 40: 87-90

Thomson WT 1997: Agricultural chemicals, Book IV: Fungicides, $12^{\text {th }}$ edition. Thomson Publications: Fresno, CA, $236 \mathrm{p}$.

Tomlin CDS 2001: The e-Pesticide manual, 12 ${ }^{\text {th }}$ Ed., Version 2.0. British Crop Protection Council, UK, 1250 p.

Tsui MTK, Chu LM 2003: Aquatic toxicity of glyphosate-based formulations: Comparison between different organisms and the effects of enviromental factors. Chemosphere 52: 1189-1197 